\title{
Progress in the pre-conceptual CAD engineering of European DEMO divertor cassette
}

\author{
Domenico Marzullo*a $^{*}$, Christian Bachmann ${ }^{\mathrm{b}}$, Domenico Coccorese ${ }^{\mathrm{a}}$, Giuseppe Di Gironimo ${ }^{\mathrm{a}}$, Paolo \\ Frosi ${ }^{c}$, Giuseppe Mazzone ${ }^{\mathrm{c}}$, Jeong Ha You ${ }^{\mathrm{d}}$ \\ ${ }^{a}$ CREATE Consortium/University of Naples Federico II, Department of Industrial Engineering (DII), Piazzale Tecchio 80 \\ - 80125 Napoli, Italy \\ ${ }^{b}$ EUROfusion, PPPT, Boltzmann Str. 2, 85748 Garching, Germany \\ 'Unità Tecnica Fusione - ENEA C.R. Frascati - via E. Fermi 45, 00044 Frascati (Roma), Italy \\ ${ }^{d}$ Max Planck Istitute for Plasma Physics, Boltzmann Str. 2, 85748 Garching, Germany
}

\begin{abstract}
This paper presents the recent progress in the pre-conceptual design activities for the EU-DEMO divertor Cassette Body, performed in the framework of the work package "Divertor" of the EUROfusion Power Plant Physics \& Technology (PPPT) program. According to Systems Engineering Principles, the divertor CAD model is reviewed, considering the updates in the DEMO configuration model presented by the Programme Management Unit (PMU) in 2017. The design parameters affected by these changes and their impact on the divertor design and on the interfaced systems are analysed. Then, the paper focuses on the integration on the new cassette geometry of the divertor subsystems. This includes the design of a "shielding liner" for cassette body and Vacuum Vessel protection, as well as the development of the cassette body-to-Vacuum Vessel fixation system. The design activities related to these main sub-systems are discussed in detail, in terms of CAD model and thermo-mechanical calculations.
\end{abstract}

\section{Introduction}

This paper presents the recent progress in the preconceptual design activities for the DEMO divertor CB. According to Systems Engineering (SE) principles [1], the divertor CAD model is reviewed, considering the updates in the DEMO configuration model presented by the Programme Management Unit (PMU) in 2017. The DEMO configuration management of CAD design data aims to support the concurrent engineering and to ensure consistency and robust working data as discussed in [2]. The conceptual design of the whole system, the design change and the interface requirements are mainly based on the initial definition of a DEMO baseline configuration model, released by PMU, containing the volume allocation and interfaces of the main sub-system [2].

The first divertor pre-conceptual design phase has been developed basing on the 2015 DEMO baseline model and the design activities have been described by authors in [3] [4]. Following the Design Change Request (DCR) procedure described in [2], in 2017 a change in the baseline DEMO configuration model has been implemented [5], mainly impacting the machine aspect ratio and providing a new volume allocation for the divertor cassette (Fig. 1).

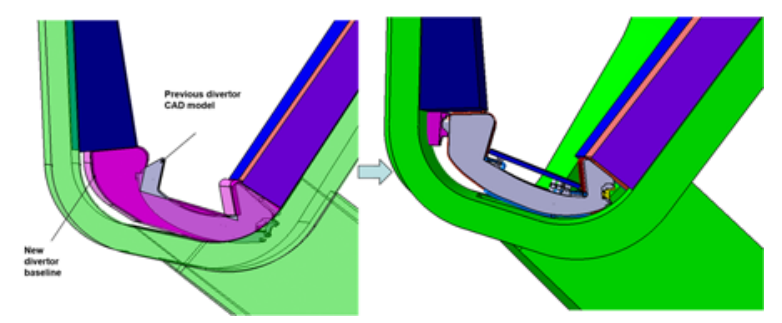

Fig. 1 (a) New baseline profile (in purple). (b) The 2017 divertor model - interface with VV and BB.
This work focuses on the design activities developed for the implementation of the divertor design in the 2017 DEMO baseline.

The divertor cassette design has been adapted to the new volume allocation and main features have been further developed, as the "shielding liner" for the vacuum pumping hole protection and the cassette-to-vacuum vessel fixation system.

\section{DEMO divertor cassette body design}

The transition to 2017 baseline for the DEMO divertor cassette design was carried on basing on the main results of the previous design phase and considering the following new high-level requirements:

- New interfaces with breeding blanket and vacuum vessel

- Inlet cooling water at $3.5 \mathrm{MPa}-180^{\circ} \mathrm{C}$

- The PFCs cooling system configuration selected during the first pre-concept design phase [3] to be integrated in the new cassette shape

- Eurofer97 material for divertor cassette: ribs thickness $20 \mathrm{~mm}$; external plate thickness $30 \mathrm{~mm}$ (considering the stress analyses performed in the first phase [6]).

Fig. 1(a) shows the divertor model resulting from the first pre-conceptual phase (grey) overlaid with the new configuration model (purple): the difference in the dimensions, especially at the inboard side, is considerable and new interfaces with Breeding Blanket and Vacuum Vessel are defined. The toroidal dimension has been also increased due to the new tokamak segmentation from 18 to 16 sectors (resulting in 48 divertor cassettes).

The divertor cassette design activities in the new baseline moved from the new reference position of the Inner Vertical Target (IVT) and Outer Vertical Target 
(OVT) (Fig. 2). The strike point on the target is in the poloidal centre of the $700 \mathrm{~mm}$ straight part of the vertical targets. The strike area is assumed to have $100 \mathrm{~mm}$ poloidal extension and the control range of the strike point is estimated $\sim \pm 300 \mathrm{~mm}$

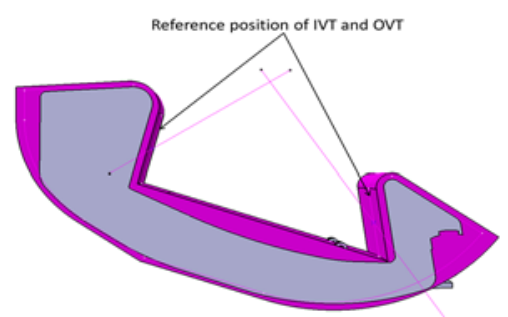

Fig. 2 Divertor design in the 2017 baseline - refence position of IVT and OVT

The cassette internal ribs structure has been assumed similar to the previous design, since no relevant changes in the pressure and operating temperature is provided. Fig. 3 shows the internal ribs layout, consisting in 4 toroidal ribs and 3 poloidal ribs driving the $\mathrm{CB}$ coolant. The ribs are $20 \mathrm{~mm}$ thick and the maximum distance between two poloidal ribs is $350 \mathrm{~mm}$.

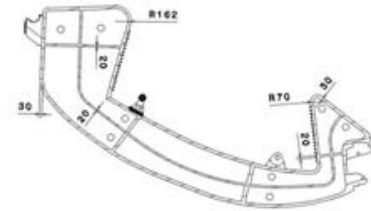

(a)

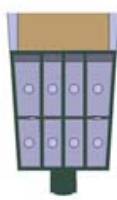

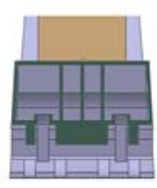

Fig. 3 (a) Divertor CB poloidal section, (b) Divertor CB toroidal section at inboard (left) and outboard (right)

Due to the different operating temperatures of the Eurofer97 CB and PFCs (see [7] and [4]), two different cooling circuits are integrated on the cassette body. From the evaluations developed during the first design phase a PFCs cooling layout has been chosen among three options [3] and it has been integrated in the new cassette design.

As discussed in section 3 and section 4, the design activities on the 2017 baseline divertor focused also on the development of main sub-components, in particular the "shielding liner" for radiation protection through the vacuum pumping hole and the cassette-to-vacuum vessel fixation system. Fig. 4 shows different views of the current divertor CAD model.

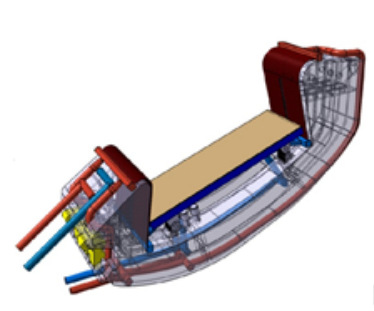

(a)

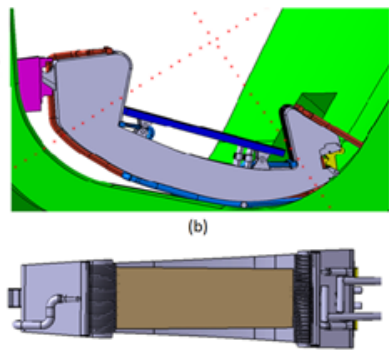

(c)

Fig. 42017 Divertor CAD model. (a) isometric view, (b) poloidal view, (c) top view
Table 1 reports the main values of volume and masses for cassette body and shielding liner, both in normal operating condition (with coolant) and in maintenance scenarios (without coolant).

Table 1

\begin{tabular}{|c|c|c|}
\hline \multirow{3}{*}{$\begin{array}{l}\text { Cassette } \\
\text { EUROFER }\end{array}$} & Density $\left[\mathrm{Kg} / \mathrm{m}^{3}\right]$ & 7750 \\
\hline & Volume $\left[\mathrm{m}^{3}\right]$ & 0,649 \\
\hline & Mass [Kg] & 5030 \\
\hline \multirow{3}{*}{ Water } & Density $\left[\mathrm{Kg} / \mathrm{m}^{3}\right]$ & 1000 \\
\hline & Volume $\left[\mathrm{m}^{3}\right]$ & 1,264 \\
\hline & Mass [Kg] & 1264 \\
\hline CB (operating condition) & Total Mass [Kg] & 6294 \\
\hline \multirow{2}{*}{ Liner } & Volume $\left[\mathrm{m}^{3}\right]$ & 0,107 \\
\hline & Mass $[\mathrm{Kg}]$ & 831 \\
\hline \multirow{2}{*}{ Water } & Volume [ $\mathrm{m}^{3}$ ] & 0,05 \\
\hline & Mass $[\mathrm{Kg}]$ & 50 \\
\hline Liner (operating condition) & Total Mass [Kg] & 881 \\
\hline CB+Liner (operating condition) & Total Mass [Kg] & 7175 \\
\hline CB+Liner (installation and RH) & Total Mass [Kg] & 5861 \\
\hline CB+Liner+PFCs (operating condition) & Total Mass [Kg] & $\approx 7600$ \\
\hline CB+Liner+PFCs (installation and RH) & Total Mass [Kg] & $\approx 6200$ \\
\hline
\end{tabular}

\section{Shielding liner design}

A protection system for the vacuum pumping hole from radiation heat and neutron flux has been investigated from the first pre-conceptual design phase, having both the shielding function and allowing for the vacuum pumping performances. Unlike in the ITER divertor; no-dome has been considered but two main options were analysed (Fig. 5). The first consists in a plate, named "shielding liner", with an internal structure similar to the water cooled blanket First Wall (FW), whose structure has already been analysed against thermal loads [8]. The second option is characterized by an embedded protection system inside the vacuum pumping hole itself. This system consists in two different components: a lamella structure acting as radiation shielding and a $\mathrm{T}$-shaped structure acting as neutron shielding.

During the first pre-conceptual design phase the shielding liner option was selected as the most simple and feasible solution to be investigated, so it has been further developed in the new divertor cassette design. The flow of plasma exhaust gases into and through the pumping hole has so far not been assessed.
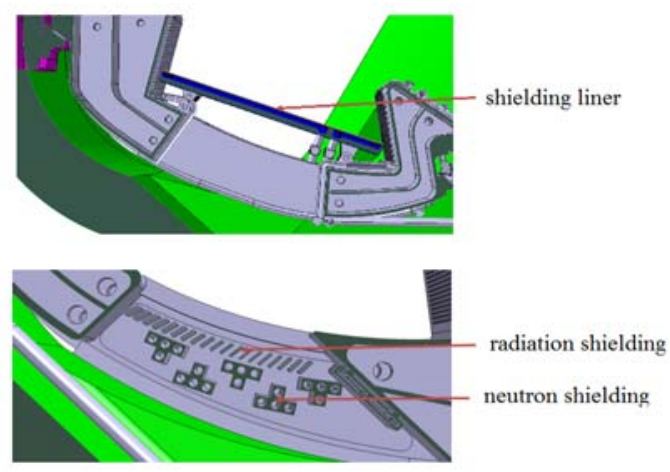

Fig. 5 Alternative solutions for vacuum pumping hole protection 
Fig. 6 shows a section of the shielding liner integrated on the divertor cassette design, highlighting the coolant flow path. The cooling water flows from the cassette (at $180^{\circ}$, 3.5 MPa) to the first shielding liner layer, coming back in the cassette through the shielding liner backplate.

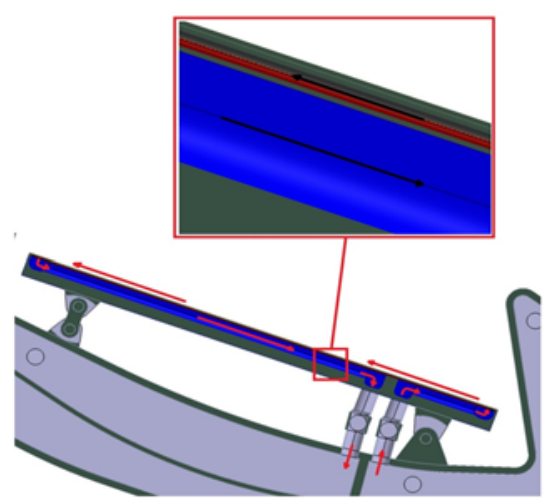

Fig. 6 Coolant flow through the shielding liner

The shielding liner is composed by four distinct layers (Fig. 7). The first layer is a $90 \mathrm{~mm}$ in thickness Eurofer97 plate crossed by semicircle-shaped slots for the coolant flow. Both second and third layers are $5 \mathrm{~mm}$ in thickness Eurofer97 plates joined together to form an array of $6 \mathrm{~mm}$ circular cooling channels to remove the significant surface heat load due to core and x-point radiation, assumed to be about $1.4 \mathrm{MW} / \mathrm{m}^{2}$. Two internal manifolds collect the coolant coming from the first layer. The Eurofer structure is covered with a $2 \mathrm{~mm}$ thick tungsten .

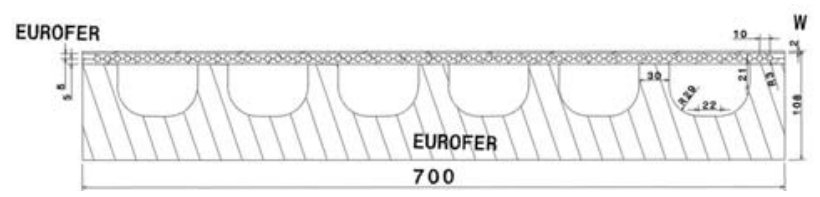

Fig. 7 Shielding liner cross section

A parametric study was performed to identify the optimal configuration of the liner backplate against thermal loads. Fig. 8 shows the starting geometry with the applied heat loads and the results for the optimal geometrical configuration identified. The input load values assumed for the analysis in terms of heat flux (Q') and power density (Q',') are summarized in Fig. 8, as well as the heat transfer convection coefficients (HTCC). The temperature on the tungsten is within an acceptable range and the temperature in the Eurofer97 does not exceed $510^{\circ} \mathrm{C}$ (for requirements on the Eurofer97 operating temperature see [7]).

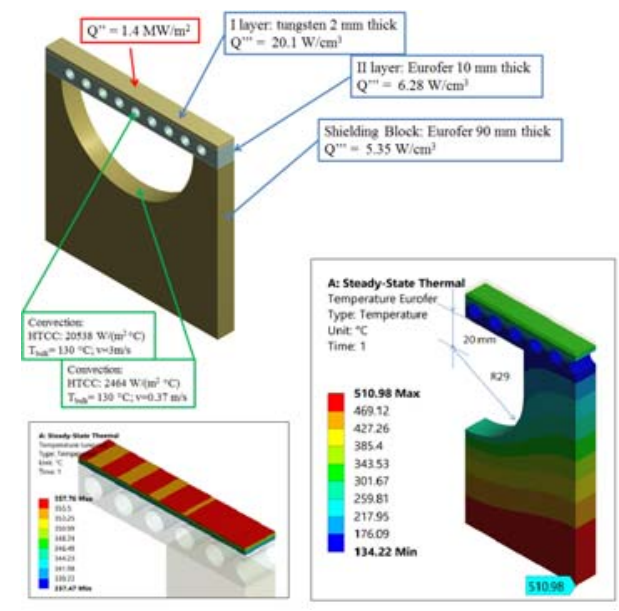

Fig. 8 Thermal analyses and geometrical optimization on the shielding liner

In parallel with the thermal analysis, parametric neutronic analyses were performed aiming to identify a possible reduction of the backplate thickness. The results showed the compliance with the vacuum vessel neutron irradiation requirements with a $60 \mathrm{~mm}$ thick Eurfofer97 backplate. Currently, structural verifications are ongoing and, basing on these results, the reduced thickness will be introduced in the next version of the CAD model.

To allow for differential thermal expansions in radial direction and, consequently, to avoid high secondary stresses, the liner supporting system consists of four multilink/link supports welded to the cassette body. This system is similar to the one used for the connection of the PFUs to the ITER divertor cassette [9]. Mainly the system consists of single hinge on the outer side and double hinge on the inner side.

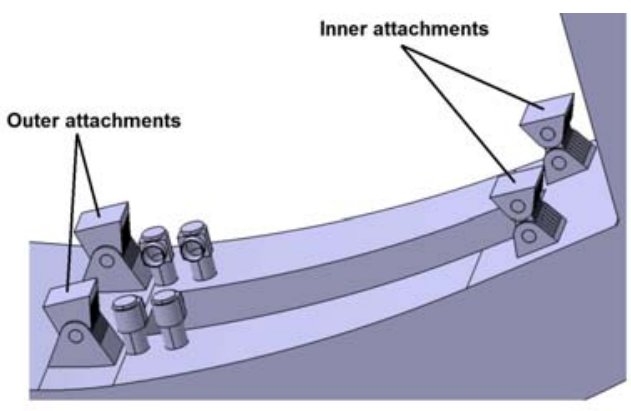

Fig. 9 Shielding liner attachments to cassette body

\section{Cassette-to-Vacuum Vessel fixation system}

The Cassette-to-Vacuum Vessel fixation system works as an interface between the divertor system and Vacuum Vessel. It shall withstand all loads due to electromagnetic events, such as disruptions or the discharge of the magnet system and it shall ensure electrical connection between the divertor and the vessel. In addition the outboard fixation system is designed with sufficient flexibility to accommodate differential thermal expansion of the vacuum vessel and $\mathrm{CB}$. Since the divertor cassettes will be replaced by means of Remote Handling $(\mathrm{RH})$ systems, it shall be compatible with the RH tools.

Several options were investigated during the first preconceptual design phase. The alternative solutions 
proposed are described in [10][11] and [3]. The results of the assessments performed on these solutions have been considered for the design of the fixation system in the 2017 baseline.

The main issue is related to the high stiffness of the $\mathrm{CB}$ and the consequent difficulties in the whole cassette preloading (as in the ITER case) for allowing the thermal expansion and ensuring the electrical connection in any load condition. To address this issue, the introduction of flexible elements at the outboard fixation system area is under evaluation. The following sections briefly describe the fixation options under evaluation in the new divertor cassette design.

\subsection{Fixation option 1}

The first fixation solution (Fig. 10) is essentially an integration of ITER-Like knuckle (adapted to the new baseline and simplified avoiding the use of internal mechanisms) on a system providing the required flexibility. The flexibility is provided by disc-spring stacked in parallel to provide $200 \mathrm{kN}$ preload at the beginning of the machine operation. Basing on the results of the studies on the material behavior under irradiation presented in [12], it is expected that the springs will provide $100 \mathrm{kN}$ force after 2 Full Power Years (FPY).

The integration of the two systems allows for more space during cassette transport and provide, at the same time, the compression needed to close gaps, avoid shaking and ensure electrical connection.
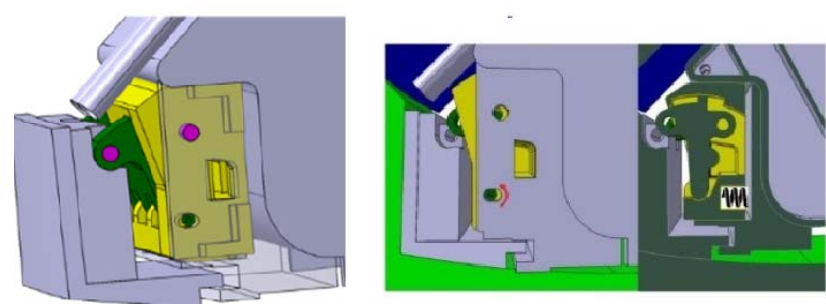

Fig. 10. Fixation option 1.

Knuckle shape is accommodated to the new volume allocation. The fixation mechanism is based on the insertion of a hydraulic jack behind the knuckle, so that it rotates pushing the cassette in radial direction. Then two pins are inserted to lock the system on cassette and vacuum vessel.

\subsection{Fixation option 2}

A second design option, currently still under development, is shown in Fig. 11. It aims to improve the flexibility of the outboard fixation system avoiding the introduction of complex spring mechanisms.

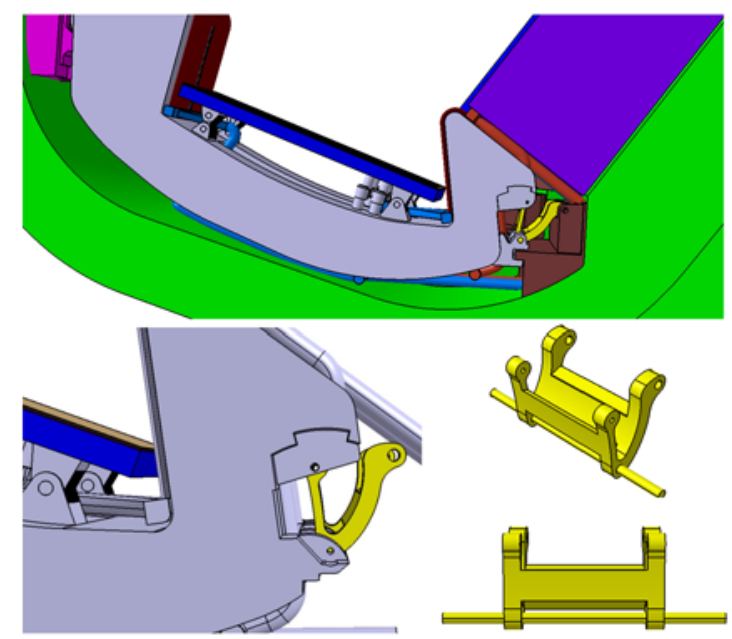

Fig. 11. Fixation option 2.

Indeed, the idea behind this new concept is to achieve a proper elasticity by the system itself allowing radial expansion and transferring vertical and toroidal loads at the same time. As for the spring, also for this element the expected degradation of elasticity after 2 fpy irradiation is evaluated according to the studies presented in [12]. From a first assessment this system should be capable to withstand the estimated maximum vertical load $\mathrm{F}_{\text {vert }}=0.9$ $\mathrm{MN}$ and the maximum radial deformation: $\mathrm{e}=4 \mathrm{~mm}$ with a radial force $\mathrm{F}_{\mathrm{rad}}=0.09 \mathrm{MN}$. Further analyses will quantify the thermal and electromagnetic loads in more detail.

\section{Conclusions}

Starting from the results of the first pre-conceptual design phase, the EU-DEMO divertor $\mathrm{CB}$ design has been developed for the 2017 EU-DEMO baseline configuration model. According to a system engineering approach, the CB design and the PFCs integration were performed combining the results of the previous evaluations (in terms of thickness and layouts) with the new volume allocation and interfaces. Alternative solutions for the vacuum vessel protection from irradiation through vacuum pumping hole have been investigated, resulting in the introduction of a shielding liner. This has been optimized from the thermal point of view, but further studies are still ongoing for vacuum pumping performance optimization.

Cassette fixation-to-vacuum vessel is still under design: several solutions have been investigated in collaboration with RM team. Further studies will focus on the outboard fixation system presented in section 4.2, which has been identified as the most feasible and simple solution to meet the main fixation requirements.

\section{Acknowledgments}

This work has been carried out within the framework of the EUROfusion Consortium and has received funding from the Euratom research and training programme 20142018 under grant agreement No 633053. The views and opinions expressed herein do not necessarily reflect those of the European Commission. 


\section{References}

[1] Di Gironimo, G., et al. "Iterative and Participative Axiomatic Design Process in complex mechanical assemblies: case study on fusion engineering." International Journal on Interactive Design and Manufacturing (IJIDeM) 9.4 (2015): 325-338.

[2] Meszaros, B., et al. "Configuration management of the EU DEMO conceptual design data." Fusion Engineering and Design 109 (2016): 1619-1623.

[3] Marzullo, D., et al. "Systems engineering approach for preconceptual design of DEMO divertor cassette." Fusion Engineering and Design 124 (2017): 649-654.

[4] You, J. H., et al. "Progress in the initial design activities for the European DEMO divertor: Subproject "Cassette"." Fusion Engineering and Design 124 (2017): 364-370.

[5] Gliss C. DEMO Baseline Model 2017. EUROFUSION IDM 2N4EZW (Private communication).

[6] Frosi, P., et al. "Structural analysis of DEMO divertor cassette body and design study based on RCC-MRx." Fusion Engineering and Design 124 (2017): 628-632.

[7] Mazzone, Giuseppe, et al. "Choice of a low operating temperature for the DEMO EUROFER97 divertor cassette." Fusion Engineering and Design 124 (2017): 655-658.

[8] Aubert, J., et al. "Development of the water cooled lithium lead blanket for DEMO." Fusion Engineering and Design 89.7-8 (2014): 1386-1391.

[9] McCallum, A. D., and J. Palmer. "Summary review of aspects of the engineering of ITER divertor PFC-to-cassette attachments." Fusion engineering and design 66 (2003): 377-381.

[10] Di Gironimo, G., et al. "Concept design of the DEMO divertor cassette-to-vacuum vessel locking system adopting a systems engineering approach." Fusion Engineering and Design 94 (2015): 72-81.

[11] Marzullo, Domenico, et al. "Design progress of the DEMO divertor locking system according to IPADeP methodology." Procedia CIRP 34 (2015): 56-63.

[12] PMI-2.1-T001 - Feasibility of in-vessel Bolts (2NACT7), private communication 